\title{
A DOCÊNCIA NA CONTEMPORANEIDADE E A FORMAÇÃO DA PESSOA DOCENTE MEDIANTE AS CONFIGURAÇÕES DA SOCIEDADE BRASILEIRA ATUAL
}

\author{
DORgIVAL GONÇALVES FERnANDES \\ Universidade Federal de Campina Grande (UFCG) \\ <dorgefernandes@yahoo.com.br>
}

DOI: 10.21439/conexoes.v11i2.1093

\begin{abstract}
Resumo. O artigo discute a formação docente assumindo-a como formação humana, centrando-se na pessoalidade do professor. Seu objetivo é refletir sobre a contemporaneidade da docência e os processos de formação para o seu exercício, considerando as vicissitudes e singularidade do tempo presente e as suas demandas educacionais. O trabalho se caracteriza como um ensaio em perspectiva filosófica. Teoricamente nos fundamentamos em autores que nos ajudam a pensar a educação na contemporaneidade, tais como Michel Foucault, António Nóvoa e Zigmunt Bauman. Consideramos a inadequação do modelo de formação vigente e apontamos as noções de cuidado de si e governo de si como pressupostos para praticar a formação e o trabalho docente, associando-se as categorias professoralidade e pessoalidade. Assim, cremos ser possível trabalhar a formação docente de modo a assegurar ao futuro professor a autonomia e os saberes necessários para lidar com as características sócio-políticas e as demandas educacionais contemporâneas.
\end{abstract}

Palavras-chaves: Docência. Formação humana. Cuidado de si. Contemporaneidade.

\begin{abstract}
The article discusses teacher training taking it as human formation, focusing on the teacher's personality. Its goal is to make a reflection about the contemporary teaching and the training processes for its exercise, considering the vicissitudes and the uniqueness of the present time and their educational demands. The work is characterized as an essay in philosophical perspective. Theoretically we have grounded in authors that help us think of education in contemporary society, such as Michel Foucault, Antonio Novoa and Zygmunt Bauman. We do consider the inadequacy of the current training model and point out the notions about self-care and self-government as assumptions for practicing the training and teaching work, associating them to the teaching and personality categories. Thus, we believe it is possible to work with teacher training to ensure the future teacher the autonomy and knowledge needed to deal with the socio-political characteristics and contemporary educational demands.
\end{abstract}

Keywords: Teaching. Human formation. Self-care. Contemporaneity.

\section{INTRODUÇÃO}

Neste artigo, elaborado como ensaio em perspectiva filosófica a partir de pesquisa bibliografia, objetivamos pensar a contemporaneidade da docência e os processos de formação para o seu exercício, considerando as vicissitudes e a singularidade do tempo presente que afetam a sociedade em seus diversos âmbitos e produzem demandas e desafios para o campo educacional. Neste sentido, buscamos problematizar a questão da forma- ção docente, suas premissas, encaminhamentos e desdobramentos, apostando na proeminência da pessoalidade como suposto basilar na constituição da professoralidade, haja vista acreditarmos que a formação docente constitui-se sob a égide da formação da pessoa.

Assim pensando, é importante perguntarmo-nos sobre a formação humana da pessoa docente, bem como o porquê e o para que de tal formação, problematizando o que a pessoa em processo de formação docente precisa 

SOCIEDADE BRASILEIRA ATUAL

aprender tendo em vista as características do contexto histórico, social e educacional no qual irá atuar profissionalmente. Assim sendo, faz-se necessário pensarmos sobre as noções de tempo e espaço onde se localizam a formação docente e o trabalho docente ensejados pelo docente formador, bem como o trabalho docente a ser realizado a posteriori pelo docente em formação.

As reflexões por nós desenvolvidas neste artigo têm como fonte de inspiração o nosso trabalho como docente formador de professores, atuante no curso de Pedagogia do Centro de Formação de Professores da Universidade Federal de Campina Grande, bem como os nossos trabalhos de pesquisa no campo educacional, mais especificamente no trato com a questão da formação de professores. Para pensarmos a formação docente assentados no contexto contemporâneo, buscamos objetivar nossas reflexões a partir de alguns dos pensadores que tomam o tempo presente como alvo de suas preocupações, centradas direta ou indiretamente sobre a formação humana e a formação docente, a exemplo de Michel Foucault, António Nóvoa e Zygmunt Bauman, entre outros.

\section{A SOLIDEZ QUE SE DESPEDE E A CRISE QUE SUBJAZ O PRESENTE DA FORMA- ÇÃO DOCENTE}

Vivemos em um tempo-mundo cuja configuração se dá entre processos diversos de mutação e de descontinuidades nos âmbitos da economia, da política e da cultura. Essa é a configuração que marca a contemporaneidade. Assim sendo, com ou sem saudades de um tempo-mundo ancorado pela fixidez e rigidez de suas estruturas e pela linearidade dos acontecimentos, pautado em certa arrogância cientifica, tecnológica, epistemológica e metodológica outrora por nós vivenciado a partir do que foi demarcado pela racionalidade moderna e estruturalista, o tempo-mundo presente requer de nós envolvidos/as com o campo da educação um novo pensamento/posicionamento acerca da nossa constituição enquanto pessoa e profissional. Na condição de professores/as, não há como não nos implicarmos e sermos implicados/as em tais mutações e descontinuidades que consubstanciam a contemporaneidade e trazem novos desafios frente às demandas e perspectivas para o aprendizado da docência e o seu exercício.

Até o início do último quartel do século passado, o educador era formado dentro das mesmas bases epistemológicas e paradigmáticas e tendo por meta os mesmos objetivos sob os quais o seu formador fora formado. Deste modo, formadores/as e formandos/as trabalhavam sob uma "grade" curricular bem definida e seguramente estabelecida visando à formação de pessoas cidadãs/profissionais ancorada em modelos prédeterminados e pré-fixados de mundo e de ser humano, a partir da qual se preparava o futuro para ser a repetição do passado.

Falamos aqui da perspectiva "clássica" de formação docente, conforme caracterização formulada por Candau (1996), que se consubstancia na perspectiva tradicional de educação. Tal formação é estruturada em um lócus definido de produção e armazenamento de conhecimentos e de sua transmissão (universidades e centros de pesquisas, entre outros) que constitui a formação inicial do docente e depois o recicla quando da sua formação continuada, e em um lócus de aplicação, a escola de educação básica. Assim, o docente é formado para ser um transmissor intermediário do conhecimento. $\mathrm{O}$ docente adquire-o de quem o sabe, ou seja, o professorformador, devendo aprender as atitudes consideradas corretas, os valores moralmente estabelecidos e os conhecimentos validados socialmente que devem ser repassados, como também o modo certo, a metodologia, de como repassar para aqueles que não sabem, no caso, os seus alunos.

De acordo com Candau (1996, p. 141): "Este tem sido o sistema habitual de formação continuada dos profissionais do magistério, sistema que ainda hoje é o mais freqüente e comumente aceito e promovido". Disto são prova as atitudes de docentes em cursos de formação continuada que temos ministrado em tempos recentes e nos quais os docentes, frente às situações de conflitos, dilemas e desafios enfrentadas no seu trabalho, nos pedem receituários e prescrições de como agir para sanar tais problemas e resolver os conflitos que enfrentam na escola, de modo geral, e na sala de aula, de modo específico, como se para cada uma destas situações houvesse um conhecimento já pronto e organizado para solucioná-la, e do qual se encontra privado, seja devido a não assimilação, de sua parte, ou o não ensinamento por parte dos seus formadores na graduação. Nesta perspectiva educativa tradicional, considerase que

as experiências e aquisições das gerações adultas são condição de sobrevivência das gerações mais novas, como também da sociedade. [...] Há aqui preocupação com o passado, como modelo a ser imitado e como lição para o futuro. Evidencia-se o caráter cumulativo do conhecimento humano, adquirido pelo indivíduo por meio de transmissão, de onde se supõe o papel importante da educação formal e da instituição escola. (MIZUKAMI 1986 p. 10-11)

Neste caso, o professor deve ser formado para atender com seu oficio a formação escolar de crianças e 
jovens, previamente idealizada por instituições sociais, tais como a família, a igreja, o mercado de trabalho e o Estado. Tais instituições alicerçam e ratificam essa formação, a qual o professor deve dar continuidade, operando a partir de uma esquematização previamente estabelecida. Assim sendo, seria de praxe o professor encontrar alunos/as convenientemente interessados/as e preparados para receber a formação dada pelo docente. Para os/as alunos/as que resistissem de algum modo a tal formação, bem como para os docentes insatisfeitos e questionadores do padrão educacional estabelecido, o aparato disciplinar estaria previamente estipulado e atento para agir sobreposto no seu poder de vigiar e punir, fazendo cumprir seu efeito de normalizar pensamentos e comportamentos, como assinalou Foucault (1987; 2010). Para tanto, esse aparato disciplinador definia o que se devia ensinar e como se devia ensinar e aprender, disciplinarizando os campos do conhecimento (as disciplinas) e disciplinando os sujeitos da educação (os modos de pensar e de agir, de ser e de fazer), em especial professores e alunos, para torná-los produtivos à ordem social, política e econômica estabelecida.

Neste caso, as diversas pedagogias formuladas no âmbito da modernidade, situadas ideologicamente à direita ou à esquerda e elaboradas sob os pilares da racionalidade iluminista, engendradas a partir do surgimento do Estado Moderno e da Escola Moderna, enquanto vontade de verdade e vontade de poder, se ocuparam da fabricação de corpos dóceis e úteis, trabalhando para a constituição de sujeitos normalizados e assujeitados na perspectiva prescrita pela Modernidade, que vigorou na perspectiva de ser convertido num modo totalizador e hegemônico até a primeira metade do século XX, conforme afirmação de Deleuze (1992).

Este estágio da Modernidade foi denominado por Bauman (2001) de Modernidade sólida. Em tal estágio, no que se refere à disciplinarização dos sujeitos, a escola se impunha objetivando o ensino da obediência. Diz este pensador:

O instinto e vontade de acatar, de seguir as ordens, de fazer o que o interesse público, tal como o definem os superiores, exige que se faça, eram as atitudes que mais necessitavam os cidadãos de uma sociedade planificada, programada, exaustiva e completamente racionalizada. A condição que mais importava não era o conhecimento transmitido aos alunos, mas a atmosfera de adestramento, rotina e previsibilidade em que se realizaria a transmissão desse conhecimento. (BAUMAN apud ALMEIDA, GOMES e BRACHT, 2009, p. 49).

Quanto à disciplinarização do campo de conhecimentos, no que diz respeito a sua organização e vigên- cia, nos diz Bauman (2002, p. 47):

O conhecimento tinha valor porque se esperava que ele durasse e a educação tinha valor na medida em que oferecia esse conhecimento de valor duradouro. A educação, que vista como um episódio circunscrito, ou como um empreendimento para toda a vida, seria uma atividade voltada para a entrega de um produto que, como qualquer outra posse, poderia ser possuída e desejada para sempre.

O ensino da obediência na modernidade clássica, ou sólida, como a nomeia Bauman configurou-se premissa dos objetivos e da ação de diversas instituições sociais que direta ou indiretamente visavam a formação dos sujeitos sociais, incluindo-se ai alunos e professores, por meio da tecnologia da disciplinarização, elemento constituinte da governamentalidade liberal. Para o filósofo Foucault (1987), a igreja, a clínica, o exército e as prisões, e efetivamente a escola, trabalharam no sentido de disciplinar o corpo e a alma dos sujeitos, objetivando constituí-los como sujeitos dóceis e produtivos, governados para reproduzirem o status quo social, político e econômico.

No caso brasileiro, podemos perceber, grosso modo e a partir de uma visão de predominância, que essa perspectiva foi objetivamente efetivada desde os primórdios da educação institucionalizada, com a ação escolar dos Jesuítas a partir de 1549 e de suas influências no pós 1759, assentada numa abordagem tradicional religiosa. Depois, mais enfaticamente a partir do século XIX, com forte influência até os dias atuais, temos a escola de base tradicional laica cuja orientação predominante se pauta no pensamento de John Herbart. No início do século XX aportou por aqui a influência do pensamento escolanovista com forte predominância das ideias de John Dewey, tendo Anísio Teixeira como o seu maior representante. Essa perspectiva de pensamento perdurou mais fortemente entre as décadas de 1930 e 1960. A partir da década de 1960, com o advento da Ditadura Militar, é erigida a escola de base tecnicista e autoritária, tendo por pressuposto psicológico e educacional o pensamento behaviorista de B. Skinner. Essa perspectiva escolar vigorou de modo efetivo até o final da década de 1970, período em que a força da Ditadura Militar começou a arrefecer.

Assim, podemos pensar que até o início da década de 1980, por um lado, a formação moral da pessoa estaria efetivada pelo conjunto das instituições sociais e pela ação regular da escola nos anos de ensino básico para aqueles e aquelas que à escola conseguiam acessar e obter sucesso, para os/as que buscavam a formação para a docência, esta formação, em sua substancialidade, centrava-se no ensinar a ensinar. 
Para tanto, ancorado numa perspectiva de conhecimento perene, estratificado e reificado, o trabalho docente visando à formação docente se consubstanciava na transmissão e aquisição de conhecimentos pedagógicos e de métodos e técnicas que melhor propiciassem a aprendizagem discente. Neste sentido, Nóvoa (1992, p. 18), contrapondo-se a essa perspectiva, afirma: "Mais do que lugar de aquisição de técnicas e de conhecimentos, a formação docente é o momento-chave de socialização e da configuração profissional".

É na perspectiva apontada por Nóvoa que se manifestam inquietações diversas de sujeitos formadores/as de educadores, operando, a partir dos anos de 1980, a produção de uma grande e rica literatura acerca da formação docente, prenhe de questionamentos e de proposições, visando responder e interferir no contexto educacional tendo em vista a democratização do acesso e da permanência da totalidade dos sujeitos educandos na escola e favorecendo uma educação de qualidade para todos. Todavia, as mudanças ocorridas no cenário mundial referentes à organização do trabalho, à revolução tecnológica e às mudanças políticas e culturais impõem a necessidade de deslocamentos do pensamento educacional no tocante às demandas e finalidades da escola, seus processos e conteúdos de ensino e aprendizagem e, consequentemente, a formação docente. Deste modo, impõe-se a necessidade de descontinuidade da política e dos procedimentos de formação docente, e de modo efetivo, de novas matrizes de pensamento ancoradas em fundamentos filosóficos outros que nos ajudem a pensar e a operar a formação docente com base em perspectivas teóricas que melhor se coadunem com as marcas e as demandas do tempo presente.

\section{AS MUTAÇÕES DO PRESENTE E OS DESA- FIOS POSTOS À DOCÊNCIA E À FORMA- ÇÃO DOCENTE}

O tempo presente vem sendo considerado como o tempo das incertezas, tal como o define Prigogine (1996), ou o tempo da modernidade líquida, como o nomeia Bauman (2001), caracterizando-se como tempo de mudanças. A sociedade contemporânea, deste modo, tem sido caracterizada por diversos autores, a exemplo de Silva (1994), pelo prefixo pós, tais como: sociedade pós-moderna, sociedade pós-estruturalista e sociedade pós-disciplinar, ou ainda como sociedade pósmoral, como referido por Gallo (2010), demarcando-se as mudanças que vêm alterando a estrutura do que foi denominada de sociedade moderna.

Kress (2006, p. 120-121), refletindo sobre as mudanças ocorridas na contemporaneidade, aponta-as na seguinte ordem:

(1) a mudança do poder do Estado para o Mercado; (2) a conseqüente mudança na subjetividade do indivíduo, de cidadão para consumidor; (3) a mudança da concepção de sociedade monocultural para a de sociedade multicultural [...]; (4) uma mudança na economia, da produção industrial de massa para a produção de nichos, por um lado, e da indústria secundária e terciária à indústria da informação/conhecimento, por outro; (5) mudanças de dois tipos na representação e na comunicação: no potencial de produção/autoria de textos e, portanto, de mudanças nas relações de autoridade; e mudanças nas formas canônicas de representação e nos meios de difusão e comunicação, envolvendo uma mudança de dominância da escrita para um uso crescente da imagem, e um deslocamento da dominância do livro e da página para a dominância da tela imagética.

As especificidades dessas mudanças apontadas por Kress incidem sobremaneira no campo da educação, dos processos de ensino-aprendizagem e na formação docente. Deleuze (1992, p. 200), ao analisar a sociedade contemporânea nos diz que essa deixou de ser organizada e gerida por um poder disciplinar para ser movida por um poder controlador, denominando a sociedade atual como sociedades de controle. Neste sentido, esse filósofo francês faz as seguintes considerações:

Encontramo-nos numa crise generalizada de todos os meios de confinamento, prisão, hospital, fábrica, escola, família [...]. Os ministros competentes não param de anunciar reformas supostamente necessárias. Reformar a escola, reformar a indústria, o hospital, o exército, a prisão; mas todos sabem que essas instituições estão condenadas, num prazo mais ou menos longo. Trata-se apenas de gerir sua agonia e ocupar as pessoas, até a instalação das novas formas que se anunciam. São as sociedades de controle que estão substituindo as sociedades disciplinares.

Em tal cenário, a escola tem sido desafiada quanto a sua organização político-estrutural, didáticopedagógica e paradigmática, bem como quanto a sua finalidade social e, assim, tem sofrido processos de mutação impostos de fora para dentro. Nesta perspectiva, Fernandes (2015) evidencia os conflitos desenvolvidos dentro da escola, provocados, por um lado, pelas dificuldades da escola em incorporar no seu cotidiano as orientações que demarcam as inovações assinaladas pelos documentos oficiais nacionais e internacionais a partir da reconfiguração do Estado e do mercado de trabalho, e por outro lado, pelas demandas e visões de si e do mundo que os estudantes, principalmente os jovens, trazem do seu mundo para dentro da escola. No rol dessas questões, Bauman (2002, p. 53) assinala que:

Foi o mundo do lado de fora da escola que cresceu muito diferente do tipo de mundo que as escolas 
costumavam preparar seus alunos. Neste novo mundo, espera-se dos humanos que eles procurem soluções privadas para os problemas gerados pela sociedade, e não que eles procurem soluções sociais para os problemas de origem privada.

Essas mudanças vêm produzindo um processo de mutação na educação, gerando uma nova crise para a educação escolar, colocando em cheque o modelo, os conteúdos, as metodologias e o próprio sentido da educação vigente inaugurada nos primórdios da modernidade. Em tal perspectiva, Gatti (2010), ao analisar 71 cursos de formação docente situados nas diversas regiões do Brasil, constata a precariedade desses cursos quanto aos conteúdos, metodologias e objetivos referentes aos processos de ensino e aprendizagem da docência, evidenciando a crise na qual se encontram a prática e o sentido da formação docente. Assim, associada a uma crise que já se arrasta há diversas décadas, ou seja, a crise calcada na elitização escolar, haja vista a incapacidade da instituição escolar em oferecer acesso a todos e a todos possibilitar a permanência e a aquisição das habilidades de leitura, escrita e cálculo e demais saberes escolares, essa nova crise refere-se ao sentido mesmo da escola frente às novas demandas alicerçadas na reconfiguração de uma sociedade marcada pela incerteza e por processos contínuos de mudanças.

Referindo-se a essa nova crise enfrentada pela escola, Teesco (1998, p. 15) faz a seguinte afirmação:

\footnotetext{
A crise da educação já não se apresenta como um fenômeno de insatisfação no cumprimento de demandas relativamente estabelecidas, mas como uma expressão particular da crise do conjunto das instâncias da estrutura social: desde o mercado de trabalho e o sistema administrativo até o sistema político, a família e o sistema de valores e crenças. A crise, em conseqüência, já não provém da forma deficiente de como a educação cumpre os objetivos sociais que lhes são atribuídos, mas, o que ainda é mais grave, do fato de não sabermos que finalidades ela deve cumprir e para onde deve efetivamente orientar suas ações.
}

Assim, em análise sobre a educação, seus fins e a atuação do educador nesse panorama atual, Bauman (2002, p. 58) nos diz:

Em nenhum outro momento decisivo da história, os educadores foram confrontados com um desafio realmente comparável ao que o divisor de águas contemporâneo apresenta. Simplesmente, jamais estivemos nesta situação antes. A arte de viver em um mundo supersaturado de informação ainda está por ser aprendida. Da mesma forma que a arte, ainda mais difícil, de preparar a humanidade para essa vida.

No sentido apregoado por Bauman, não nos é mais pertinente pensarmos a formação docente na perspec- tiva de adequar a escola aos alunos para que a aprendizagem dos saberes escolares seja efetivada para estes. Por outro lado, não seria salutar pensar a formação do docente na perspectiva de que este trabalhe na adequação dos alunos à escola para que esta possa efetivar as aprendizagens que oferta, ou seja, nem a adequação da escola aos alunos e nem a adequação dos alunos à escola parecem não mais dar os frutos desejados pela escola. Neste caso, apesar de propalarmos a autonomia dos professores na realização do seu trabalho, bem como propalarmos o empodeiramento do sujeito estudante, ainda continuamos vendo ser materializada uma formação docente que teima em preparar professores para reproduzirem o modus operandi moderno de se lidar com o processo educacional, realimentando a formação docente como imperativo de ensinar a ensinar, ensinar o fazer docente a partir de um ou outro modelo. $\mathrm{Na}$ verdade, parece-nos não haver modelos a seguir, e sim, faz-se necessário criar alternativas localizadas e contextualizadas para a ação docente, a partir da reinvenção de si da pessoa docente e, consequentemente, a reinvenção do fazer docente. Sendo assim, urge problematizarmos os paradigmas clássicos que orientaram e ainda orientam a formação docente, profanar as suas premissas, seus encaminhamentos e desdobramentos e vislumbrarmos a produção de outros pensamentos possíveis.

Sendo assim, diante de uma conjuntura social e educacional que se nutre de incertezas e mudanças, como poderíamos pensar a questão da docência e da formação para a docência? Sabemos que neste panorama mutante que se tornou a contemporaneidade, qualquer caminho que possamos perspectivar será de difícil travessia, como difícil também será encontrar um porto seguro onde possamos ancorar nossos anseios e sonhos e dirimir angústias tantas, afinal, como afirma Nóvoa (2004, p. 17), "falar de educação nos tempos que correm obriga-nos, a todos, a um exercício de grande modéstia e humildade". Mas, creio que podemos nos aportar em algumas das sinalizações apontadas por pensadores, tais como Michel Foucault e António Nóvoa, tomando como referência a formação da pessoa para pensarmos acerca da formação docente.

No tocante à formação docente, temos ao longo desses últimos séculos pensado o docente enquanto sujeito profissional, nas suas dimensões política e técnica, e negligenciado a dimensão pessoal do docente e a sua formação humana, na qual se ancoram o político e o profissional. Caso exemplar dessa negligência é a falta de preocupação, nos cursos de formação docente, com o pensar acerca da saúde e do bem estar docente. Não 

SOCIEDADE BRASILEIRA ATUAL

tem sido raro o caso de professores que apresentam sintomas exacerbados de stress, de estafa física e emocional, problemas de afonia, rouquidão, calos e fissuras nas suas cordas vocais que afetam um dos seus principais instrumentos de trabalho, a voz. Podemos considerar também os entraves que esses problemas de stress e estafa física e emocional acarretam para a sua capacidade de reflexão e autoformação que engendram o seu aperfeiçoamento intelectual, emocional e espiritual.

$\mathrm{Na}$ contemporaneidade, considerando-se as suas características que provocam incertezas dos rumos, sentidos e procedimentos da educação, pensar a formação da pessoa do professor é imprescindível, haja vista que é da sua dimensão pessoal que o professor se valerá para pensar a si mesmo e se situar profissionalmente de modo produtivo e crítico na formação dos seus discentes.

Neste sentido, é necessário construir, como assinala Nóvoa (2004, p. 21), "uma teoria da pessoalidade no interior mesmo de uma teoria da profissionalidade". Nessa perspectiva, o pensador português afirma

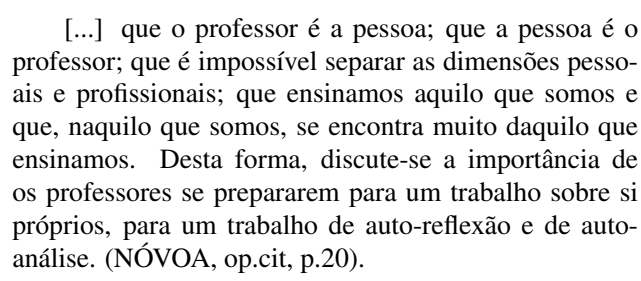

[...] que o professor é a pessoa; que a pessoa é o professor; que é impossível separar as dimensões pessoais e profissionais; que ensinamos aquilo que somos e que, naquilo que somos, se encontra muito daquilo que ensinamos. Desta forma, discute-se a importância de os professores se prepararem para um trabalho sobre si próprios, para um trabalho de auto-reflexão e de autoanálise. (NÓVOA, op.cit, p.20).

Retomando aqui as ideias de Bauman acerca das dificuldades para se viver e para ensinar a viver na contemporaneidade e as ideias de Nóvoa quanto à necessidade dos professores pensarem-se a si mesmo, situamos no processo de formação docente a importância e a necessidade de considerarmos o pensamento de Michel Foucault no que se refere à formação humana a partir do preceito do cuidado de si. Isto porque frente aos processos de mutação que demarcam o pensar-fazer educativo contemporâneo, não há mais caminho certo, aprioristicamente prescrito, a ser seguramente seguido. Neste caso, é necessário que os sujeitos da educação produzam caminhos e modos de fazer educação que os levem a conduzirem-se no mundo de maneira coerente com o seu desejo, ancorado num certo senso ético e estético de viver que constitui o cuidado de si. Este cuidado se consubstancia no governo de si e no ocupar-se consigo mesmo, considerando a existência do si e dos outros.

Nesse sentido, segundo assevera Silva (2012, p.01):

A chave analítica do cuidado de si tal como problematizada no pensamento tardio de Foucault propicia uma reflexão sui generis sobre o sujeito da educação, capaz inclusive de retomar os ideais clássicos da formação humana, embora prescindindo de uma concepção de natureza humana fixa e essencialista.

Na perspectiva apontada por Silva, os sujeitos em processo de formação para a docência devem implicarse duplamente com o preceito do cuidado de si devido a sua condição de estudantes e de futuros docentes, aprendendo a desenvolver um projeto ético e estético de existência que deve alicerçar-se no cuidado de si consigo para poder cuidar dos outros, os seus futuros alunos, e preparar estes para que aprendam a cuidar de si mesmo. Nas palavras de Foucault (2010, p. 55), "Não se pode cuidar de si sem passar pelo mestre, não há cuidado de si sem a presença de um mestre. Porém, o que define a posição do mestre é que ele cuida do cuidado que aquele que ele guia pode ter de si mesmo".

$\mathrm{O}$ cuidado de si, segundo esse pensador francês (Op.cit, p. 12), "é uma forma de atenção, de olhar. Implica uma certa maneira de estar atento ao que se pensa e ao que se passa no pensamento". Ainda segundo esse filósofo, o preceito do cuidado de si favorece a emergência de práticas de liberdade a partir das quais os sujeitos podem produzir uma ética e estética da existência na qual a vida se configure como uma obra de arte (FOUCAULT, 2013). Assim, a partir da noção do cuidado de si, a vida não poderia ser ensinada, o ensino se pautaria na preparação do sujeito docente e discente para que aprendam a cuidar de si, assumindo para si a construção de caminhos que os levem à produção inventariada do seu próprio viver dentro de um patamar ético que objetive o governo de si por si e para si.

\section{CONCLUSÃO}

Neste artigo, evidenciamos modos de formação docente herdados da perspectiva moderna, ainda vivenciados na atualidade, e apontamos as limitações e incoerências de tais modos em relação às caracterizações da contemporaneidade. Contrapondo-se a tal perspectiva, advogamos a produção de modos de formação docente centrados na noção folcaultiana do cuidado de si, com acento na relação pensada por António Nóvoa entre pessoalidade e professoralidade.

Acreditamos que pensar a formação docente centrando-a na noção foucaultiana do cuidado de si mesmo, sob a convergência da pessoalidadeprofessoralidade no contexto contemporâneo contempla todas as dimensões formativas do sujeito docente e as diversas modalidades de conhecimentos e saberes requeridas para o exercício da docência. De início, deve-se salientar a apreensão por parte dos discentes dos conhecimentos básicos fundamentais, tais como 
A DOCÊNCIA NA CONTEMPORANEIDADE E A FORMAÇÃO DA PESSOA DOCENTE MEDIANTE AS CONFIGURAÇÕES DA SOCIEDADE BRASILEIRA ATUAL

os domínios da leitura, da escrita e do cálculo. Tais conhecimentos, dada a deficiência da escola básica na realização de sua função instrumental, nas últimas décadas, têm se tornado um problema importante nos processos de formação docente. Na seqüência, assinala-se a apreensão problematizada dos conhecimentos instrumentais pertinentes ao campo da didática e das metodologias de ensino. E por fim, conhecimentos pertencentes aos campos sociológicos, filosóficos, históricos, econômicos, culturais e psicológicos a serem inseridos em análises locais para que o docente possa ter autonomia e possibilidades de efetivar decisões, direcionar encaminhamentos e propor soluções para os problemas que emergem na vivência da sua atuação profissional.

Desse modo, os conhecimentos escolares devem ser considerados como relevantes para que os sujeitos discentes produzam suas condutas de modo otimizado, individual e coletivamente, tendo em vista a governamentalidade de si. É esta governamentalidade que pauta a noção do cuidado de si e se desdobra no cuidado dos outros frente à diversidade e pluralidade dos estilos de vida e dos modos de existência que marcam a complexidade da ação educacional na sociedade contemporânea. Assim sendo, a formação docente com base nos pressupostos da modernidade parece-nos não apontar caminhos pertinentes e suficientes para empreendermos práticas educativas coerentes com os desafios do tempo presente.

\section{REFERÊNCIAS}

ALMEIDA, F. Q. de; GOMES, I. M.; BRACHT, V. BAUMAN \& A EDUCAÇÃO. Belo Horizonte: Autêntica, 2009.

BAUMAN, Z. MODERNIDADE LÍQUIDA. Tradução de Plínio Dentzien. Rio de Janeiro: Jorge Zahar, 2001.

. DESAFIOS EDUCACIONAIS DA

MODERNIDADE LÍQUIDA. Rio de Janeiro: Revista TB, 2002.

CANDAU, V. M. F. Formação continuada de professores: tendências atuais. In: REALI, Aline M. de M. R.; MIZUKAMI, Maria da Graça N. FORMAÇÃO DE PROFESSORES: Tendências atuais. São Carlos: EDUFSCar, 1996.

DELEUZE, G. CONVERSAÇÕES. Tradução de Peter Pal Pelbart. Rio de Janeiro: 34, 1992.

FERNANDES, D. G. Relatório de Estágio de Pósdoutorado. Faculdade de Educação da Universidade de São Paulo, A CONSTITUIÇÃO DA JUVENTUDE ESTUDANTIL NA CONTEMPORANEIDADE

BRASILEIRA: Intersecções entre disciplinamento e agenciamento discente. 2015. 122 p.

FOUCAULT, M. VIGIAR E PUNIR: Nascimento da prisão. Tradução de Raquel Ramalhete. 39a . Ed. Petrópolis: Vozes, 1987.

"Cuida de ti mesmo". Entrevista com

Michel Foucault. Tradução do CEPAL.

Instituto Humanitas Unisinos. 2013. Disponí-

vel em: <http://www.ihu.unisinos.br/noticias/ 517228-cuida-de-ti-mesmo-entrevista-com-michel-foucault> Acesso em: 13 de janeiro de 2014.

GALLO, S. Ética e Educação em uma Sociedade Pós-Moralista. In: DALBEN, Ângela I. L. de Freitas et al. (Orgs.). Convergências e Tensões no Campo da Formação e do Trabalho Docente. Belo Horizonte: Autêntica, 2010.

GATTI, B. A. LICENCIATURAS: Crise sem mudança? In: DALBEM, Angela I. L. de Freitas et al (Orgs.). Convergências e Tensões no Campo da Formação e do Trabalho Docente. Belo Horizonte: Autêntica, 2010.

KRESS, G. O ensino na era da informação: entre a instabilidade e a integração. In: GARCIA, Regina Leite e MOREIRA, Antonio Flávio B. (Orgs.). CURRÍCULO NA CONTEMPORANEIDADE: incertezas e desafios. Tradução de Silvana C. Leite, Beth Honorato e Dinah de A. Azevedo. 2a . Ed. São Paulo: Cortez, 2006.

MIZUKAMI, M. da G. N. ENSINO: As abordagens do processo. São Paulo: E.P.U, 1986.

NÓVOA, A. Formação de professores e profissão docente. OS PROFESSORES E A SUA FORMAÇÃO. Lisboa: Publicações Dom Quixote, 1992. 15-33 p.

Currículo e Docência: a pessoa, a partilha, a prudência. In: GONSALVES, Elisa Pereira; CARVALHO, Maria Eulina P. de; PEREIRA, Maria Zulieide da C. CURRÍCULO E CONTEMPORANEIDADE: questões emergentes. Campinas: Alínea, 2004.

PRIGOGINE, I. O FIM DAS CERTEZAS: tempo, caos e as leis da natureza. Tradução de Roberto Leal Ferreira. São Paulo: EdUNESP, 1996.

SILVA, N. M. A. da. A REATIVAÇÃO DA NOÇÃO DE CUIDADO DE SI E A IDEIA DE FORMAÇÃO 
HUMANA: Uma recepção tardia de Foucault? In: Anais da ANPED. $35^{a}$ Reunião. Porto de galinhas, PE, outubro de 2012. Disponível em: $<$ http://35reuniao.anped.org.br/trabalhos/125-gt17>. Acesso em: 17 de janeiro de 2014.

SILVA, T. $O$ adeus às Metanarrativas Educacionais. O SUJEITO DA EDUCAÇÃO: estudos foucaltianos. Petrópolis: Vozes, 1994.

TEESCO, J. C. O NOVO PACTO EDUCATIVO:

educação, competitividade e cidadania na sociedade moderna. Tradução de Otacílio Nunes. São Paulo: Ática, 1998. 